\title{
Broadening the Positive Psychological Capital Construct: An Asian Cultural Perspective
}

\author{
Fatima Ashraf ${ }^{1}$ \\ Muhammad Asif Khan ${ }^{2}$
}

\begin{abstract}
Asian management thinkers and academician have called for Asian management researchers to employ Asian thought and culture in research (Fang, 2010; Meyer, 2006; Zhang, Waldman, $\mathrm{Han}$, \& $\mathrm{Li}$, 2015). In view of these scholarly calls, this research aimed at, firstly, validating the positive psychological capital construct within work settings of Pakistan; secondly, broadening the positive psychological capital construct through adding dimensions of wisdom and gratitude that are typified in the Asian collectivist culture with the purpose of augmenting organisational behaviour theory and practice, specifically within Asia. Data were obtained from 285 employees working in the telecommunication industry. Analytical procedures involved gauging the construct's psychometric properties using factor analysis procedures. In line with expectations, results confirmed validation of the positive psychological capital construct in the Pakistani context. Results also revealed that wisdom and gratitude are indeed dimensions of the positive psychological capital construct. This study mainly confirms the psychological capital construct within Pakistan and also broadens the construct by identifying and testing for additional positive strengths, rooted in the Asian culture, that compose this construct. Additional theoretical/academic implications and notable strengths and limitations of the study are provided at the end.
\end{abstract}

Keywords: Asian management, Asian culture, positive psychological capital, wisdom, gratitude.

\section{INTRODUCTION}

While global organisations vehemently strive to sustain competitiveness amid excessive rivalry and competition (Schraeder \& Jordan, 2011; Zhang, Waldman, Han, \& Li, 2015), Asian markets particularly represent vast economic challenges and opportunities today (Moore \& Wang, 2014; Patel, 2016; Schmitt, 2015). Clearly, organisational behaviour and human research management research - both global as well as Asian - revolves around remedying relevant issues. In such times, elevated competition and the resultant doubt and vagueness has urged customary human resource management to shift from conventional, mainstream human resource management style to contemporary and improved human resource methods with the aim of strengthening, energizing, and motivating their workforce - a workforce that is exhausted and strained following of decades of organizational change, overhauling, and downscaling (Bartlett \& Ghoshal, 2002; Luan, Tien, \& Chi, 2013). The upcoming Asian business opportunities have more than ever emphasized the importance of fresh and planned human resource management approaches. Indeed, the contemporary worker is obliged to be concerned for his individual development and enactment (Van de Heuvel, Demerouti, Schaufeli, \& Bakker, 2010). Reasonably, such an environment focuses on the individual level practices (Wright \& McMahan, 2011).

1- PhD Scholar, Shaheed Zulfikar Ali Bhutto Institute of Science and Technology Islamabad. email: fasaifi77@gmail.com. 2- Professor, Shaheed Zulfikar Ali Bhutto Institute of Science and Technology, Islamabad. 
In present times, human resource managers must strategize to profit from a broader grasp of the settings and milieus under which their human resources exist and toil with the purpose of eliminating the tests and ordeals that workers face for outstanding work performance. In essence, it is crucial that Asian strategic human resource management should gain from the employee level strengths that certify determined work and consequently organisational performance. This transformation in human resource management focus highlights the need to examine and utilize positive employee level strengths for determined work performance within Asian settings. In line with this argument, Fletcher and Fang (2006) suggested that Asian management scholars and managers must merge the distinctiveness present in Asian emerging markets' cultures within their plans for success. Scholars (Fang, 2010, Warner, 2014) also recommended that Asian scholars should make novel, original theoretical contributions via confidence and valor. It is thus argued that developing Asian businesses and prospects will benefit from innovative Asian human resource management approaches and strategies that have been developed within Asian thought and culture.

A review of earlier literature shows that positive organizational behaviour provides the underpinnings for the idea of distinguishing, nurturing and promoting employee strengths (Seligman (1998; Seligman \& Csikszentmihalyi, 2000). Positive psychology aims to avert the managerial and academic focus on negative constructs at work and instead emphasize employee strengths and qualities so as to encourage and promote positivity and success rather than to focus on alleviating employee weaknesses and flaws (Seligman, 2000; Gable \& Haidt, 2005). Employing the positive organizational behaviour theory, Luthans, Norman, Avolio, and Avey (2008) developed the construct of positive psychological capital. These researchers recommended that positive psychological capital at work assists work performance and minimizes negative work outcomes such as employee absence (Luthans, 2002b; Avey, Luthans, \& Jensen, 2009). The proposition gained importance as empirical research on positive psychological capital showed the soundness of this construct and its relationship with organizational variables (Luthans, 2002a, 2002b).

The domain of organisation behaviour has been recently introduced to positive organisational behaviour theory and positive psychology, which focus on development and employment of constructive, assessable individual virtues and strengths for employee and organisational performance enhancement and benefit (Luthans, 2002a ; Schaufeli \& Salanova, 2007; Seligman \& Csikszentmihalyi, 2000; Walumba, Avolio, \& Hartnell, 2010). The positive psychology field has, therefore, grown in terms of development of rigorous theory and empirical studies and finally progressed to practical employment at work.

Positive psychological capital is a relatively recently emerged and developed construct within positive organisational behaviour that is centered on augmenting work performance. A substantial volume of empirical research surrounding positive psychological capital has proven utility of this construct for desirable employee and organisational performance (e.g. Abbas, Raja, Darr, \& Bouckenooghe, 2014; Avey, Luthans, \& Jensen, 2009; McArdle, Waters, Briscoe, \& Hall, 2007; Walumba, Avolio, \& Hartnell, 2010). 


\section{Statement of the Problem}

Following theory and research surrounding positive psychological capital, Luthans, Norman, Avolio, and Avey (2008) recommended that the construct should be broadened through adding further dimensions of psychological capital. Given the need to bring in Asian thought in research related to human resource management practices as discussed earlier on the one hand, and recognizing the call for broadening the positive psychological capital construct on the other hand, this study theoretically establishes and empirically tests two more dimensions, i.e. wisdom and gratitude to the psychological capital construct. Although earlier literature has suggested that wisdom and gratitude are positive strengths, these have not been theoretically proposed, or empirically examined as forming the positive psychological capital construct. This research article attempts to bridge this existing research gap by suggesting and empirically examining wisdom and gratitude as valid dimensions of the positive psychological capital construct.

\section{Research Objectives}

In line with the argument offered above, this research is guided by two-fold aim. Firstly, building on theory and empirical research, this study aims at adding dimensions of wisdom and gratitude to the positive psychological capital construct - an existing construct within organisational behaviour. Alongside, it also empirically tests for validity of the positive psychological construct in the context of Pakistan, a nation among Asian markets.

\section{Research Questions}

This study aims to answer the following research questions:

- Do wisdom and gratitude form additional dimensions of the positive psychological capital construct?

- Can the positive psychological capital construct be validated in the Pakistani context?

\section{Significance of the Study}

This study, by confirming factorial validity of the positive psychological capital construct in the Pakistani context, would pave the path for future studies. Specifically, future studies focusing on positive psychological capital that are conducted in Pakistan may identify this construct as a valid context in the Pakistani culture. In addition, if wisdom and gratitude are confirmed as psychological capital dimensions, researchers may employ a holistic measurement of this construct in their studies. Likewise, policy makers and trainers may utilize the broadened psychological capital in designing and formulating their policies and trainings.

\section{LITERATURE REVIEW}

\section{Positive Psychological Capital - Existing Definition}

Luthans and Avolio (2009, p. 300) defined positive psychological capital as, "an individual's positive psychological state of development characterized by: (1) having confidence (self efficacy) to take on and put in the necessary effort to succeed at challenging tasks; (2) making a positive attribution (optimism) about succeeding now and in the future; (3) persevering toward goals, and when necessary, redirecting paths to goals (hope) in order to succeed; and (4) when beset by problems and adversity, sustaining and bouncing back and even beyond (resilience) to attain success". 
Despite the established utilities of this construct, as discussed earlier, studies that specifically aim at validating this construct in the business environment of Pakistan are scarce. To bridge this gap, the following hypothesis is proposed:

H1: Confidence, hope, optimism, and resilience are dimensions of psychological capital construct.

In addition, Peter and Seligman (2004) suggested that wisdom and gratitude are important positive virtues. However, wisdom and courage, as components of a higher-order construct is a novel idea. Reasonably, merging of positive virtues as wisdom and gratitude under a single broader construct would enhance measurement of that construct. In particular, it is proposed that wisdom and gratitude should be treated as components of positive psychological capital within a relevant culture, i.e. a culture that comprises, and arguably, encourages these virtues within itself. Work environments may be enriched as application of wisdom and gratitude would be relatively uncomplicated in a culture that encourages these elements. The following discussion offers the theoretical foundation for wisdom and gratitude as forming two distinct dimensions of psychological capital. Wisdom and gratitude are conceptualised as dimensions of psychological capital, drawing from the positive organisational behaviour theory.

\section{Added Dimension: Wisdom}

A review of earlier literature (e.g. Ardelt, 2004; Cameron, Dutton, \& Quinn, 2003; Elbaz \& Haddoud, 2017; Kramer, 1990; Rowley, 2006) shows that scholars have treated wisdom as a positive, promising concept. Wisdom is rooted in the human capacity to be honourable and beneficial to others through being altruistic, perceptive and insightful in private and open affairs. A good number of studies (e.g. Hawkins, 1991; Katzenbach \& Smith, 2015; Kupers, 2016) have empirically proven the benefits of practicing wisdom within organisations. While studies have verified the usefulness of wisdom within organisations, there exists a need for examining wisdom as part of a broader, higher-order construct.

Arguably, a highly collectivist culture encourages and fosters elements of wisdom within social interactions including connections and exchanges within organisations. The Pakistani Asian culture, as concluded by Hofstede, (1983) is typified by collectivism. Interestingly, Warner (2015) has specifically stressed the importance of wisdom in organisational practices for Asian managers, who must keep a free mindset when working in the global world economy. This highlights the contextual pertinence of wisdom as a unique cultural element of psychological capital. Hence, wisdom is reasoned as a dimension of psychological capital. Specifically, this study suggests that wisdom is a positive virtue, which is part of a higher-order construct, i.e. positive psychological capital, hence it hypothesises that wisdom will form the fifth dimension of the positive psychological capital construct.

H2: Wisdom will form the fifth dimension of the higher-order construct of positive psychological capital.

\section{Added Dimension: Gratitude}

Rooted in theology and philosophy, the gratitude concept has clear theoretical and empirical foundation. Scholars agree that gratitude is as a unique, positive ability rooted in morality, motivation, and procreation (Algoe \& Haidt, 2009; Bussin \& Christos, 2017; Fredrickson,

94 July-Dec $2017 \quad$ Volume $15 \quad$ Number $2 \quad$ JISR-MSSE


2004; Hasan, Mortimer, Lings, \& Neale, 2017; McCullogh, Emmons, \& Tsang, 2002; Weiner, Russell, \& Lerman, 1979). It involves an overall propensity to distinguish and react with appreciative feeling to generosity obtained from others, or when obtains some form of gain from others that related negatively with stress and anxiety and positively with positive concepts. These studies clearly establish the distinctiveness, and the positive, modifying quality of gratitude. Moreover, gratitude is linked with spirituality and religiosity (Allport, Gillespie \& Young, 1948; Gilligan \& Furness, 2006; Machell, Disabato, \& Kashdan, 2016; Rentala, Lau, \& Chan, 2017; Ruini, 2017) that are, arguably, dominant aspects of the theological Asian culture.

Albeit the recognition by scholars that gratitude is a constructive, prolific individual strength, specific effects of gratitude at the workplace need empirical exploration. Given these hypothetical, pragmatic, and cultural indications, gratitude is argued as a component of the overall positive psychological capital.

H3: Gratitude will form the sixth dimension of the higher-order construct of positive psychological capital.

\section{RESEARCH DESIGN}

\section{Instruments}

Established and validated instruments were used to measure study variables. The existing, well-known four psychological capital dimensions of confidence, hope, resilience, and optimism were measured using Luthans, Avolio, Avey, and Norman's (2007) Psychological Capital Questionnaire (PCQ, self-rater version). This instrument assesses confidence, hope, resilience, and optimism on a 6-point Likert type agreement scale from 'strongly disagree' (1) to 'strongly agree' (6).

Wisdom, an added psychological capital dimension in this study, was tapped using the Three Dimensional-Wisdom scale (3D-WS) developed and validated by Ardelt (2003). This scale comprises of three components of wisdom - cognitive (14 items), reflective (12 items), and affective (13 items), hence the original 3D-WS has 39 items tapping wisdom. Given the length of the 3D-WS and its disparity with respect to the number of items in other psychological capital dimensions, it was necessary to shorten the scale. For this purpose, five subject matter experts were approached and asked to select the most suitable items to measure wisdom. Subsequently, eleven items were selected to measure wisdom. Respondents were asked to rate the items based on their state at that time of providing their replies along a 5-point Likert type agreement scale ranging from 'strongly agree' (1) to 'strongly disagree' (5).

Gratitude, the second proposed psychological capital dimension was tapped with McCullough, Emmons, and Tsang's (2002) six-item Gratitude Questionnaire (GQ-6) that is a seven-point Likert type agreement scale with scale anchors ranging from ' 1 ' meaning 'strongly disagree' to '7' meaning 'strongly agree'.

\section{Sample and Data Collection Procedure}

Five organisations within the telecommunication industry were selected basis of convenience. Human resource manager of each organisation was approached and introduction and academic purpose of the study was explained to them. Five hundred coded questionnaires along with a 
cover letter were provided to each human resource manager, who was to pass on and collect questionnaires from employees. Ethical considerations during the data collection procedure included voluntary participation in the study, and ensuring confidentiality and anonymity of study respondents. Three hundred filled questionnaires were collected from each human resource manager through agreement at a pre-decided date. The average age of the study participants was 37.5 years, $72 \%$ were men and $28 \%$ were women. Returned questionnaires with majorly unfilled items were dropped from analysis, resulting in 285 usable replies. The effective response rate being $60 \%$.

\section{ANALYSIS AND DISCUSSION}

\section{Reliability of the Research Instrument}

Internal consistency of items of overall psychological capital, its existing four dimensions of confidence, hope, resilience, optimism, and two added dimensions of wisdom and gratitude was gauged using Cronbach's alpha to examine whether items pertaining to each of the dimensions fit theoretically (Nunnally, Bernstein, \& Berge, 1967). Table 1 presents the Cronbach's alpha and bivariate correlations for psychological capital and its dimensions.

Table 2: Cronbach's Alpha Coefficients, Bivariate Correlations for Study Variables

\begin{tabular}{|c|c|c|c|c|c|c|c|c|}
\hline Variable & Cronbach's $\alpha$ & 1 & 2 & 3 & 4 & 5 & 6 & 7 \\
\hline 1. Psy Cap (38) & $.88 * *$ & 1 & & & & & & \\
\hline 2. Confidence (6) & $.80 * *$ & $.35^{*}$ & 1 & & & & & \\
\hline 3. Hope (6) & $.72 * *$ & $.27 *$ & $.22 *$ & 1 & & & & \\
\hline 4. Resilience (6) & $.71 * *$ & $.29 *$ & $.31 * *$ & $.19^{*}$ & 1 & & & \\
\hline 5. Optimism (6) & $.80 * *$ & $.31 * *$ & $.33 * *$ & $.37 * *$ & $.41 *$ & 1 & & \\
\hline 6. Wisdom (11) & $.75^{* *}$ & $.26^{* *}$ & $.21 *$ & $.28 *$ & $.23^{*}$ & $.18^{*}$ & 1 & \\
\hline 7. Gratitude (4) & $.79 *$ & $.30 *$ & $.27 *$ & $.22 *$ & $.30 *$ & $.40 *$ & $.39 *$ & 1 \\
\hline
\end{tabular}

PsyCap=Psychological capital

$\mathrm{N}=285$.

$* \mathrm{p}<.000, * * \mathrm{p}<.001$.

\section{Construct Validity}

As Table 1 displays, Cronbach's alpha coefficients were within the acceptable range of 0.7 (Nunnally, 1978), suggesting that the items of the research instrument were internally consistent. Bivariate correlations between study variables were in accordance with expectations. It was expected that overall psychological capital would relate positively with its existing four dimensions of confidence, hope, resilience, and optimism, and with added two dimensions of wisdom and gratitude, and that the six psychological capital dimensions would correlate positively with each other. Overall, all correlations were moderate, ranging from .18 to .41 (Cohen, 1988). Since all six psychological capital dimensions of confidence, hope, resilience, optimism, and wisdom and gratitude had moderate, positive correlations with overall positive psychological capital, evidence for convergent validity is found. Also, these moderate, positive correlations between the six psychological capital dimensions show that these six dimensions are conceptually and empirically distinct from each, pointing to evidence for discriminant validity among psychological capital dimensions (Cronbach \& Meehl, 1955; Westen \& Rosenthal, 2003).

96 July-Dec 2017 Volume $15 \quad$ Number $2 \quad$ JISR-MSSE




\section{Factorial Dimensionality of the Research Instrument}

\section{Exploratory Factor Analysis}

Several scholars (Eysenck, 1950; Field, 2005; Guilford, 1946) have stressed the importance of examining internal structure of a construct to validate. Factor analytic method helps establish sound psychometric properties of subscales (Reise, Waller, \& Comrey, 2000). Moreover, exploratory factor analysis was also deemed necessary in view of the language and context difference, as the subscales had been tested in varied contexts and culture earlier that might have implied a possible alteration in original internal factor structure of psychological capital sub-scales or dimensions. Factor analysis procedures recommended by Piedmont (2014) were employed to test whether items of each subscale were uni-dimensional, i.e. formed a single dimension when subjected to exploratory factor analysis. Specifically, each subscale (dimension) of positive psychological capital was separately subjected to principal component analysis with varimax rotation. One factor solution was extracted in each case, followed by examination of factor loadings, for which 0.36 was specified as the cut-off criteria (Field, 2005). Significance of Bartlett's test of sphericity and Kaiser-Meyer-Olkin measure of sampling adequacy were noted. Table 2 shows results principle component analysis of items of positive psychological capital dimensions, with varimax rotation, extracting one-factor solution.

Table 2: Principle Component Analysis of Items of Positive Psychological Capital Dimensions

\begin{tabular}{|c|c|c|c|c|}
\hline Psychological capital items & $\begin{array}{l}\text { Factor } \\
\text { loadings }\end{array}$ & $\begin{array}{l}\text { KMO measure } \\
\text { of sampling } \\
\text { adequacy }\end{array}$ & $\begin{array}{l}\text { Bartlett's } \\
\text { test of } \\
\text { sphericity }\end{array}$ & $\begin{array}{l}\text { Explained } \\
\text { variance }\end{array}$ \\
\hline Confidence (6) & & .84 & $2.78^{*}$ & $77 \%$ \\
\hline $\begin{array}{l}\text { 1. I feel confident analysing a } \\
\text { long-term problem to find a solution. } \\
\text { 2. I feel confident in representing my } \\
\text { work area in meetings with management. } \\
\text { 3. I feel confident contributing to } \\
\text { discussions about the organization's strategy. } \\
\text { 4. I feel confident helping to set targets/goals } \\
\text { in my work area. } \\
\text { 5. I feel confident contacting people outside } \\
\text { the organization (suppliers, customers) to } \\
\text { discuss problems. } \\
\text { 6. I feel confident presenting information } \\
\text { to a group of colleagues. }\end{array}$ & $\begin{array}{l}.85 \\
.62 \\
.66 \\
.72\end{array}$ & & & \\
\hline
\end{tabular}




\section{Hope $(\mathbf{6}$; modified subscale $=\mathbf{5}$ items $) \quad .81 \quad 2.21^{*} \quad 61 \%$}

1. If I should find myself in a jam at work, I could think of many ways to get out of it.

2. At the present time, I am energetically pursuing my work goals.

3 . There are lots of ways around any problem. . $30 * * *$ 4. Right now I see myself as being pretty successful at work.

5. I can think of many ways to reach my current work goals.

6. At this time, I am meeting the work goals that I have set for myself.

.61

\section{Resilience (6)}

1. When I have a setback at work, I do not have trouble recovering from it.

2. I usually manage difficulties one way or another at work.

3. I can be "on my own," so to speak, at work if I have to.

4. I usually take stressful things at work in stride.

5. I can get through difficult times at work because I've experienced difficulty before. 6. I feel I can handle many things at a time at this job.

Optimism (6, modified subscale $=5$ items $)$

.72

.72

1. When things are uncertain for me at work, I usually expect the best.

2. Nothing can go wrong at work for me.

3. I always look on the bright side of things regarding my job.

4. I'm optimistic about what will happen to me in the future as it pertains to work. 5. In this job, things work out the way I want them to.

6. I approach this job as if "every cloud has a silver lining." 


\section{Wisdom $(11$ modified subscale $=9$ items $)$}

1. It is better not to know too much about things that cannot be changed.

2. A person either knows the answer to a question or he/she doesn't.

3 . You can classify almost all people as either honest or crooked.

4. I like solving a problem if I know it has a solution.

5. Simply knowing the answer rather than understanding the reasons for a problem is fine. .77 6. I sometimes find it difficult to see things from another person's point of view.

7. When I look back on what has happened to me, I can't help feeling resentful.

8. People make too much of the feelings and sensitivity of animals.

9. There are some people I know I would never like.

10. Sometimes I don't feel very sorry for other people when they are having problems. 11. Sometimes when people are talking to me, I find myself wishing that they would leave.

Gratitude (4

1. I have so much at work to be thankful for.

2. If I had to list everything about work that I felt grateful for, it would be a very long list. 3. I am grateful to a wide variety of people at work.

4. As I get older I am able to appreciate the people and situations that are part of my work history.

$\mathrm{N}=285$.

$* p<.000$, ** $p<.001$,

$* * *$ Low item loading, deleted item.

Table 2 shows that factor loadings of items of confidence, hope, optimism, resilience, wisdom, and gratitude were moderate to high with the exception of a few items that were dropped from further analysis due to low factor loading (Field, 2005). Specifically, all six items of the confidence dimension were retained; one item ("there are lots of ways around any problem") was removed from the hope subscale resulting in five retained items to measure the hope subscale; all six items of the resilience subscale were retained as factor loadings were adequate, one item from the optimism subscale ("I'm optimistic about what will happen to me in the near future as it pertains to work") was dropped due to low factor loading resulting in five retained items to measure the optimism subscale; two items from the wisdom subscale 
("when I look back on what happened to me, I can't help feeling resentful", and "people make too much of the feelings and sensitivity of animals") displayed item loadings below the acceptable criteria of 0.4 , resulting in nine items to assess wisdom; four items measured the gratitude subscale. In all, four items with low item loadings were dropped from the overall psychological capital construct.

\section{Confirmatory Factor Analysis}

All items retained in exploratory factor analysis were subjected to confirmatory factor analysis to confirm the factor structure of psychological capital, its existing four dimensions of confidence, hope, resilience, optimism, and added dimensions of wisdom and gratitude, using AMOS 20.0. Items of each construct were specified to their first-order factors (dimensions) and the first-order factors were specified to the second-order factor of psychological capital. Six fit indices were examined to see if the data fit well (Chen, Sousa, \& West, 2005; Hinkin, 1995; Wymer \& Alves, 2012). Table 3 presents results of confirmatory factor analysis of study variables.

Table 3: Results for Confirmatory Factor Analysis of Study Variables

\begin{tabular}{|c|c|c|c|c|c|c|c|c|c|}
\hline Variable/item & $\chi^{2}$ & $d f$ & RMSEA & CFI & $G F I$ & $A G F I$ & $\begin{array}{l}\text { Factor } \\
\text { loadings }\end{array}$ & $C R$ & $A V E$ \\
\hline Psychological capital & 28.59 & 19 & .034 & .94 & .90 & .89 & & 0.96 & 0.71 \\
\hline Confidence & & & & & & & $.91 *$ & & \\
\hline Hope & & & & & & & $.84 *$ & & \\
\hline Optimism & & & & & & & $.80^{*}$ & & \\
\hline Resilience & & & & & & & $.81 *$ & & \\
\hline Wisdom & & & & & & & $.92 *$ & & \\
\hline Gratitude & & & & & & & $.77 *$ & & \\
\hline
\end{tabular}

$\mathrm{N}=285$

$* p<0.01$.

Table 3 shows that the second-order model for psychological capital with its six first-order factors of confidence, hope, optimism, resilience, wisdom, and gratitude exhibited good model fit. All factor loadings loaded significantly $(\mathrm{p}<0.01)$ on their respective latent factor, and were above the threshold of 0.5 (Hair, Black, Babin, \& Andersen, 2010). Adequate estimates of greater than 0.7 and 0.5 were found for composite reliability and average variance extracted (Malhotra \& Dash, 2011), establishing sufficient reliability and validity. Hence, results from confirmatory factor analysis of psychological capital with its established four dimensions of confidence, hope, resilience, and optimism, and suggested dimensions of wisdom and gratitude offered sufficient evidence for validation of the construct. This evidence suggests that, as hypothesized, wisdom and gratitude are dimensions of psychological capital, and that overall psychological capital should be measured using the existing four dimensions of confidence, hope, resilience, and optimism suggested by Luthans, Avolio, Avey, and Norman (2007) , and additional dimensions of wisdom and gratitude that the present study has proposed and empirically tested. 


\section{CONCLUSION}

Taking together the results of reliability analysis, inter-correlations between positive psychological capital, its existing four dimensions of confidence, hope, optimism, resilience, and added dimensions of wisdom and gratitude, and evidence from exploratory and confirmatory factor analysis, it may be inferred that sub-scales of wisdom and gratitude are internally consistent, and that wisdom and gratitude are valid, additional dimensions of positive psychological capital as they moderately correlate positively with all dimensions of psychological capital and with overall positive psychological capital, indicating construct validity. Results clearly support factorial dimensionality of the psychological capital construct with its existing four and added dimensions of wisdom and gratitude is clearly indicated. In sum, validity of the positive psychological capital construct with its existing four dimensions of confidence, hope, optimism, resilience, and theory-based and empirically-tested dimensions of wisdom and gratitude, is established, following construct validation procedures elaborated earlier. Hypotheses $\mathrm{H} 1, \mathrm{H} 2$ and $\mathrm{H} 3$ are thus accepted. Alternatively, positive psychological capital is measured through six dimensions of confidence, hope, optimism, resilience, wisdom, and gratitude.

\section{Strengths and Limitations}

Important strengths and limitations of this study should be delineated. An important strength of this study is that wisdom and gratitude as added dimensions of psychological capital are theory-driven, i.e. have been conceptualized as psychological capital components using the positive organisational behaviour theory. Statistical testing and validation procedures followed this theoretical foundation, thereby complying with Hinkin's (1995) recommendation for reliance on both theory and empirical testing.

Despite the elaborated strengths, certain limitations of this study should be pointed out. The empirical validation of wisdom and gratitude as components of psychological capital should be considered as initial validation because statistical procedures for scale validation are complex and lengthy (Schwab, 1980). Additionally, since the data used in this study was captured from organisations in Pakistan, validity of the factor structure of psychological capital, specifically the wisdom and gratitude dimensions, should be pertained with caution as Asian country cultures may be generalized, yet differences across specific Asian cultures may exist.

\section{Managerial and Organisational Implications}

In view of Hofstede's (2007) conclusion that the Asian culture is typified with collectivism, wisdom and gratitude are, arguably, conventional elements of such a collectivist culture that emphasizes lifelong familial and societal cohesiveness, loyalty, and security. The outcomes of employing aspects of wisdom and gratitude within collectivist Asian cultures can offer promising interventions and trainings designed by managers within the emerging Asian markets. Given that for community within collectivist cultures, the 'sticking glue' is the practical wisdom and gratitude that members have with one another. Managers and strategizers may refine and develop cultural elements at work that are traditional positive virtues and strengths. 
Specifically, trainings, workshops, and seminars that aim to recognize, develop, employ, and value positive psychological capital as composed of confidence, hope, optimism, resilience, and wisdom, gratitude may be organized to boost work performance. These trainings and interventions should aim at building on, enhancing and polishing specific ways to boost wisdom and gratitude at work with the aim of augmenting employee and group performance through enhancing group cohesiveness, safety, and allegiance.

For policy makers, decision makers, and strategizers within Asian emerging markets, a notable implication is that policies and strategies should center on creating an organisational culture that is rich in wisdom and gratitude, beside confidence, hope, optimism, and resilience; a national culture rooted in positive virtues of wisdom and gratitude among societal members would not be so difficult to create and sustain. Investments to create such a culture are promising and fruitful with long-term effects.

\section{Future Research Suggestions}

Future research may conduct further validation of wisdom and gratitude as components of psychological capital, as rigorous validation of a construct may require several phases (Schwab, 1980). Future research may also validate whether wisdom and gratitude are specifically valid for other Asian emerging markets as India, Bangladesh, etc., other than Pakistan. As explicated previously, unique differences between different nation may expectedly exist. Moreover, future research may add more theoretically driven dimensions to the psychological capital construct for broadening its measurement from cultural and contextual perspective.

\section{REFERENCES}

Abbas, M., Raja, U., Darr, W., \& Bouckenooghe, D. (2014). Combined effects of perceived politics and psychological capital on job satisfaction, turnover intentions, and performance. Journal of Management, 40(7), 1813-1830.

Algoe, S. B., \& Haidt, J. (2009). Witnessing excellence in action: The "other-praising" emotions of elevation, gratitude, and admiration. Journal of Positive Psychology, $4,105-127$.

Allport, G. W., Gillespie, J. M., \& Young, J. (1948). The religion of the post-war college student. The Journal of Psychology, 25(1), 3-33.

Ardelt, M. (2 004). Wisdom as expert knowledge system: A critical review of a contemporary operationalisation of an ancient concept. Human Development, 47, 257-285.

Avey, J. B., Luthans, F., \& Jensen, S. M. (2009). Psychological capital: A positive resource for combating employee stress and turnover. Human Resource Management, 48(5), 677-693.

Bartlett, C. A \& Ghoshal, S. (2002). Building competitive advantage through people. Sloan Management Review, 4(2), 32-74.

Bussin, M., \& Christos, D. (2017). Employee engagement required for success. HR Future, 2017(May 2017), 36-37.

Cameron, K. S., Dutton, J. E., \& Quinn, R. E. (2003). An Introduction to Positive Organizational Scholarship. San Francisco: Berrett-Koehler.

Chen, F. F., Sousa K. H., \& West, S. G. (2005). Testing measurement invariance of second-order factor models. Structural Equation Modeling, 12(3), 471-492. 
Cohen, J. (1988). Statistical Power Analysis for Behavioural Sciences (2 ${ }^{\text {nd }}$ ed.). New York: Academic Press.

Cronbach, L. J., \& Meehl, P. E. (1955). Construct validity in psychological tests. Psychological Bulletin, 52, 281-302.

Elbaz, A. M., \& Haddoud, M. Y. (2017). The role of wisdom leadership in increasing job performance: Evidence from the Egyptian tourism sector. Tourism Management, $63,66-76$

Eysenck, H. J. (1950). Criterion analysis an application of the hypothetico-deductive method in factor analysis. Psychological Review, 57, 38-53.

Fang, T. (2010). Asian management research needs more self-confidence: Reflection on Hofstede (2007) and beyond. Asia Pacific Journal of Management, 27, 155-170.

Field, A. (2005). Discovering Statistics with SPSS. (2 ${ }^{\text {nd }}$ ed.). London: Sage.

Fletcher, R. \& Fang, T. (2006). Assessing the impact of culture on relationship creation and network formation in emerging Asian markets. European Journal of Marketing, $40(3 / 4), 430-446$.

Fredrickson, B. L. (2004). Gratitude, like other positive emotions, broadens and builds. In R. A. Emmons, McCullough, M. E. (Eds.). The Psychology of Gratitude (pp. 145-166). New York: Oxford University.

Gable, S. L., \& Haidt, J. (2005). What (and why) is positive psychology? Review of General Psychology, 9(2), 103-110.

Guilford, J. P. (1946). New standards for test evaluation. Educational Psychological Measurement, 6, 427-439.

Hair, J., Black, W., Babin, B., \& Anderson, R. (2010). Multivariate data analysis (7 th $^{\text {ed.). }}$ Prentice-Hall, Inc. Upper Saddle River, NJ: USA.

Hasan, S. F, Mortimer, G., Lings, I. N., \& Neale, L. (2017). Examining the antecedents and consequences of gratitude. Journal of Services Marketing, 31(1), 34-47.

Hawkins, P. (1991). The spiritual dimension of the learning organisation. Management Education and Development, 22(3), 172-187.

Hinkin, T. R. (1995). A review of scale development practices in the study of organizations. Journal of Management, 21(5), 967-988.

Hofstede, G. (1983). The cultural relativity of organisational practices and theories. Journal of International Business Studies, 14(2), 75-89.

Katzenbach, J. R., \& Smith, D. K. (2015). The wisdom of teams: Creating the high-performance organization. Harvard Business Review Press.

Kramer, D. A. (1990). Conceptualising wisdom: The primacy of affect-cognition relations. In R. J. Sternberg (Ed.), Wisdom. Its Nature, Origin, and Development (pp. 279-316). Australia: Cambridge University.

Kupers, W. (2016). A handbook of practical wisdom: Leadership, organization and integral business practice. New York: Routledge.

Luan, C. J., Tien, C., \& Chi, Y. C. (2013). Downsizing to the wrong size? A study of the impact of downsizing on firm performance during an economic downturn. The International Journal of Human Resource Management, 24(7), 1519-1535.

Luthans F. (2002a). Positive organizational behavior: Developing and managing psychological strengths. Academy of Management Executive, 16, 57-72.

Luthans, F. (2002b). The need for and meaning of positive organizational behavior. Journal of Organizational Behavior, 23(6), 695-706. 
Luthans, F., \& Avolio, B. J. (2009). The "point" of positive organisational behaviour. Journal of Organisational Behaviour, 30, 291-307.

Luthans, F., Avolio, B. J., Avey, J. B. \& Norman, S. M. (2007). Positive psychological capital: Measurement and relationship with performance and satisfaction. Personnel Psychology, $60,541-572$.

Luthans, F., Norman, S. M., Avolio, B. J. \& Avey, J. B. (2008). The mediating role of psychological capital in the supportive organizational climate - employee performance relationship. Journal of Organizational Behavior, 29, 219-238.

Machell, K. A., Disabato, D. J., \& Kashdan, T. B. (2016). Buffering the negative impact of poverty on youth: The power of purpose in life. Social Indicators Research, 126(2), 845-861.

Malhotra N. K., \& Dash S. (2011). Marketing Research, an Applied Orientation. London: Pearson Publishing.

Martin, A. J. (2011). Courage in the classroom: Exploring a new framework predicting academic performance and engagement. School Psychology Quarterly, 26(2), 145.

McArdle, S., Waters, L., Briscoe, J. P., \& Hall, D. T. T. (2007). Employability during unemployment: Adaptability, career identity and human and social capital. Journal of Vocational Behavior, 71(2), 247-264.

McCullogh, M. E., Emmons, R. A., Tsang, J. (2002). The grateful disposition: A conceptual and empirical topography. Journal of Personality and Social Psychology, 82(1), 112-127.

Meyer, K. E. (2006). Asian management research needs more self-confidence. Asia Pacific Journal of Management, 23, 119-137.

Moore, T. \& Wang, P. (2014). Dynamic linkage between real exchange rates and stock prices: Evidence from developed and emerging Asian markets. International Review of Economics \& Finance, 29, 1-11.

Nunnally, J. (1978). Psychometric Theory. New York: McGraw-Hill.

Nunnally, J. C., Bernstein, I. H., \& Berge, J. M. T. (1967). Psychometric Theory. New York: McGraw-Hill.

Pae, H. K. (2012). A psychometric measurement model for adult English language learners: Pearson Test of English Academic. Educational Research and Evaluation, 18, 211- 229.

Patel, T. (2016). Multiparadigmatic Studies of Culture: Needs, Challenges, and Recommendations for Management Scholars. European Management Review, 14(1), 83-100.

Peterson, C., \& Seligman, M. E. P (2004). Character Strengths and Virtues: A Handbook and Classification. Oxford University Press: New York.

Piedmont, R. L. (2014). Factorial validity. Encyclopedia of Quality of Life and Well-Being Research, 2184-2194. doi: 10.1007/978-94-007-0753-5_984.

Reise, S. P., Waller, N. G., Comrey, A. L. (2000). Factor analysis and scale revision. Psychological Assessment, 12(3), 287-297.

Rentala, S., Lau, B. H. P., \& Chan, C. L. (2017). Association Between Spirituality and Depression Among Depressive Disorder Patients in India. Journal of Spirituality in Mental Health, 1-13.

Rowley, J. (2006). What do we need to know about wisdom? Management Decision, 44(9), 1246-1257.

Ruini, C. (2017). Gratitude, Spirituality and Meaning: Their Clinical Implications. In Positive Psychology in the Clinical Domains. 179-203. Springer International Publishing. 
Schaufeli, W.B. \& Salanova, M. (2007). Work engagement: An emerging psychological concept and its implications for organizations. In S.W. Gilliland, D.D. Steiner \& D.P. Skarlicki (Eds.), Research In Social Issues In Management 135-177. Charlotte, NC: Information Age Publishing.

Schmitt, B. (2015). The "new wave" in studying Asian markets and consumers. Marketing Letters, 26(3), 261-264.

Schraeder, M., \& Jordan, J. (2011). Managing performance. Journal for Quality Participation, 34(2): 4-10.

Schwab, D. P. (1980). Construct validity in organization behavior. In B. M. Staw \& L. L. Cummings (Eds.), Research in organizational behavior. 2(1),3-43). Greenwich, CT: JAI Press.

Seligman, M. E. P. (1998). Building human strengths: Psychology's forgotten mission. APA Monitor, 29(1). Retrieved from: http://www.apa.org/monitor/jan98/pres.

Seligman, M. E. P., \& Csikszentmihalyi, M. (2000). Positive psychology, an introduction. American Psychologist, 55(1), 5-14.

Van den Heuvel, M., Demerouti, E., Schaufeli, W. B. \& Bakker, A. B. (2010). Personal resources and work engagement in the face of change. In Houdmont, J. (Ed.), Occupational Health Psychology, European Perspectives on Research, Education and Practice. 4(1),124-150. Chichester: Wiley.

Walumba, F, O., Avolio, B. J. \& Hartnell, C. A. (2010). An investigation of the relationships among leader and follower psychological capital, service climate, and job performance. Personnel Psychology, 63, 937-963.

Warner, M. (2014). Culture and management in Asia. London, New York: Routledge.

Warner, M. (2015). Pragmatic strategy: Eastern wisdom, global success/Chinese leadership/ Thoughts on economic development in China/The history of ancient Chinese economic thought. Asia Pacific Business Review, 21(4), 555-557.

Weiner, B., Russell, D. \& Lerman, D. (1979). The cognition-emotion process in achievement-related contexts. Journal of Personality and Social Psychology, $37,1211-1220$

Westen, D., \& Rosenthal, R. (2003). Quantifying construct validity: Two simple measures. Journal of Personality and Social Psychology, 84(3), 608-618.

Wright, P. M., \& Mcmahan, G. C. (2011). Exploring human capital: Putting 'human' back into strategic human resource management. Human Resource Management Journal, 21(2), 93-104. DOI: 10.1111/j.1748-8583.2010.00165.

Wymer, W., \& Alves, H. M. (2012). A review of scale development practices in nonprofit management and marketing. Interdisciplinary Approach to Economics and Sociology, 5(2), 143-151.

Zhang, Y., Waldman, D. A., Han, Y. L., \& Li, X. B. (2015). Paradoxical leader behaviors in people management: Antecedents and consequences. Academy of Management Journal, 58(2), 538-566. 


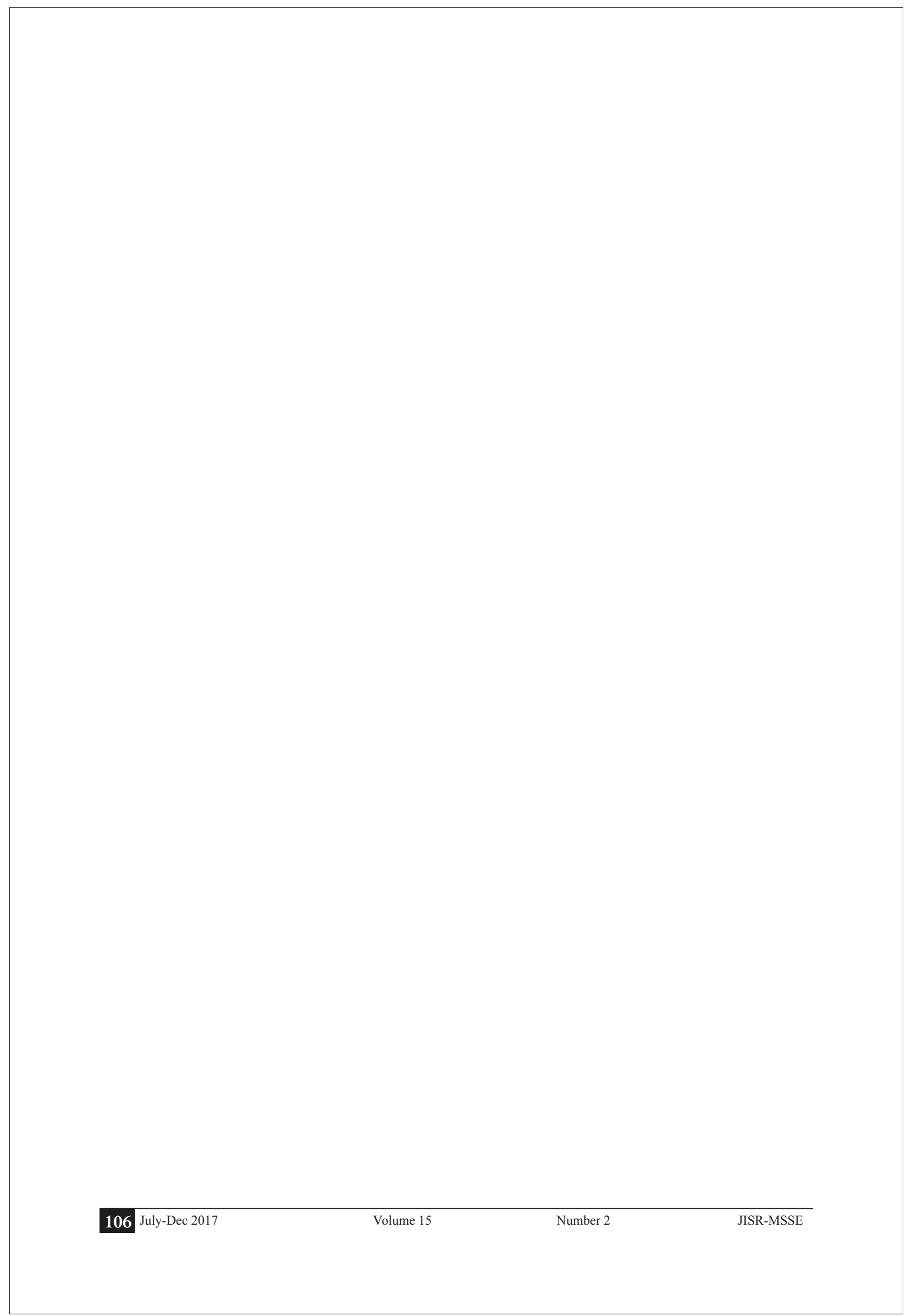

